\title{
Subjetividades juveniles y narrativas escolares en el Telebachillerato Comunitario en México
}

Youth subjectivities and school narratives in the Community Telebachillerato of Mexico

\author{
Volumen 21, Número 2 \\ Mayo - Agosto \\ pp. 1-30
}

\section{Rocío Elizabeth Salgado Escobar}

\section{Citar este documento según modelo APA}




\title{
Subjetividades juveniles y narrativas escolares en el Telebachillerato Comunitario en México
}

\author{
Youth subjectivities and school narratives in the Community Telebachillerato of Mexico
}

\section{Rocío Elizabeth Salgado Escobar ${ }^{1}$}

\begin{abstract}
Resumen: En México, la obligatoriedad de la Educación Media Superior decretada en 2012 todavía es tarea pendiente en los contextos rurales y conurbados en donde los Telebachilleratos Comunitarios son una política educativa en expansión para incorporar jóvenes antes excluidos del sistema escolar. El Telebachillerato tiene sus orígenes en 1980, no obstante, la modalidad escolarizada y comunitaria cuenta con apenas cinco generaciones, $y$ aún es escasa la investigación desde la perspectiva de sus propios actores. Por esta razón, el presente estudio se propuso comprender cómo las condiciones de acceso a este tipo educativo signan las subjetividades juveniles y su experiencia escolar. El estudio de corte cualitativo-interpretativo se desarrolló al sur del estado de México, durante el bienio noviembre 2018-2020, bajo una metodología dialógico-reflexiva desplegada en un taller de narrativa con un grupo de sexto semestre. Las sesiones fueron videograbadas, transcritas y sistematizadas en tres líneas analíticas: condiciones de acceso a la escolaridad, subjetividades juveniles y participación en la escuela. Los resultados visibilizan itinerarios escolares marcados por la implementación precaria de una modalidad en donde la población de jóvenes se enuncia a sí misma como la más abatida, pero en la que también construye otros modos de subjetividad a través de la participación para demandar mejor infraestructura, incidencia en la normatividad escolar y procesos pedagógicos basados en el reconocimiento. Se concluye que las subjetividades y narrativas escolares son fundantes de comunidades educativas construidas en el diálogo reflexivo y emergentes sentidos juveniles que se ponen en juego en el ejercicio del derecho a la educación.
\end{abstract}

Palabras clave: juventud, educación media superior, política educativa, participación

\begin{abstract}
In Mexico, the requirement for upper secondary education decreed in 2012 is still a pending task in rural and marginalized contexts where "Telebachilleratos comunitarios" are an expanding educational policy to incorporate young people previously excluded from the school system. The "Telebachillerato" has its origins in 1980, however, the school and community modality has only five generations and there is still little research from the perspective of its own actors. Therefore, the present study aimed to understand how the conditions of access to this type of education indicate the subjectivities of youth and their school experience. The qualitative-interpretative study was developed in the south of the state of Mexico, during the biennium November 2018-2020 under a dialogicreflexive methodology deployed in a narrative workshop with a sixth semester group; the sessions were videotaped, transcribed and systematized in three analytical lines: conditions of access to schooling, youth subjectivities and participation in school. The results make visible school itineraries marked by the precarious implementation of a modality in which young people declare themselves the most despondent, but in which they also construct other modes of subjectivity through participation to demand better infrastructure, impact on school norms and pedagogical processes based on recognition. It is concluded that school subjectivities and narratives are founders of educational communities built on reflective dialogue and emerging youth meanings that are activated in the exercise of the right to education.
\end{abstract}

Key words: youth, high school, educational policy, participation

\footnotetext{
${ }_{1}$ Docente-investigadora del Instituto Superior de Ciencias de la Educación del Estado de México, División Académica Tejupilco, Estado de México, México. ORCID https://orcid.org/0000-0003-3954-8164
}

Dirección electrónica: rocio.salgado@isceem.edu.mx

Artículo recibido: 24 de noviembre, 2020

Enviado a corrección: 25 de marzo, 2021

Aprobado: 19 de abril, 2021

Los contenidos de este artículo están bajo una licencia Creative Commons 


\section{Introducción}

En la última década, la Educación Media Superior (EMS) en México ha enfrentado reformas educativas y modificaciones constitucionales que han incidido en su estructura, fines y funciones educativas y sociales. En este proceso han surgido nuevas modalidades con el propósito de avanzar en la cobertura y la obligatoriedad decretada en 2012; a la par se han ido configurando diferenciadas condiciones de acceso, así como nuevas o renovadas relaciones, experiencias y significaciones de las juventudes con la institución escolar.

Es interés del artículo visibilizar las narrativas escolares de jóvenes estudiantes del Telebachillerato Comunitario (TBC), una modalidad que tiene su antecedente en los Telebachilleratos Estatales surgidos en la década de 1980 y que, a diferencia de estos, y de otros subsistemas de EMS a distancia, ofrece una educación escolarizada. Los planteles se han instalado prioritariamente en contextos desfavorecidos donde enfrentan la carencia de infraestructura, además de condiciones económicas y simbólicas precarias del estudiantado, las cuales signan sus subjetividades entre descréditos, demandas y propuestas juveniles que se hace necesario valorar en la concreción de la política educativa y la construcción de su experiencia escolar y social.

El trabajo se inscribe en una investigación colegiada llevada a cabo entre noviembre de 2018-2020 en un Cuerpo Académico $(C A)^{2}$ a través de la Línea de Generación y Aplicación de Conocimiento Educación, escuela y contextos comunitarios. El objetivo del estudio fue visibilizar las condiciones y experiencias de escolaridad que signan las subjetividades juveniles en el TBC a partir de sus narrativas, las cuales con un carácter dialógico e interactivo favorecen escuelas participativas entre demandas y acciones para el pleno ejercicio del derecho a la educación.

EI TBC es una opción del tipo media superior del Sistema Educativo Nacional que tiene su referente histórico en el Telebachillerato Estatal fundado a finales del siglo XX en el estado de Veracruz, donde siguió el modelo de las escuelas telesecundarias que imparten educación básica en poblaciones rurales dispersas a través de programas televisivos producidos por el Estado (Weiss, 2017a). Actualmente, el Telebachillerato en la modalidad comunitaria conserva

2 El CA se denomina Educación y Poder. Acciones con grupos en condición de pobreza y contextos de vulnerabilidad, adscrito al Instituto Superior de Ciencias de la Educación del Estado de México y registrado en el Programa Federal para del Desarrollo Profesional Docente (PRODEP). El CA tiene una trayectoria de más de una década en el campo de investigación escuela y juventud, focalizando en el ejercicio del derecho a la educación y en la incidencia político-pedagógica en los niveles secundaria y media superior en contextos urbanos y rurales desfavorecidos. Articula otras dos Líneas de Generación y Aplicación de Conocimiento: Políticas educativas con grupos vulnerables y Cultura escrita y vínculo pedagógico. 
la lógica de ampliar la cobertura de la EMS en localidades menos favorecidas, elevar el nivel educativo de la población y fomentar el arraigo de las juventudes a sus comunidades a través de la capacitación para el Desarrollo Comunitario.

EI TBC ofrece el servicio de bachillerato prioritariamente en zonas rurales con menos de 2500 habitantes, así como en zonas marginales que no disponen del servicio de bachillerato en 5 kilómetros a la redonda. El estudio de Weiss (2017a) destaca que actualmente hay un número apreciable de estas escuelas en zonas urbanas periféricas, pues hay mucha demanda que no pueden absorber otros tipos de servicio educativo, de ahí que constituyan "la opción para los que no pueden aspirar a otros espacios" (p. 16).

Por lo regular, el TBC ocupa las instalaciones de escuelas telesecundarias donde, sin ser una modalidad a distancia como aún son estas, opera dentro de sus espacios a contra turno, lo que permite aminorar el costo de su fundación, aunque no garantizar las condiciones para su óptima operación (Weiss, 2017a). El financiamiento del salario de los tres profesores que integran la planta docente de los TBC está a cargo del gobierno federal durante el primer año y a partir del segundo año es 50\% federal y 50\% estatal; empero, hay entidades en donde también participan otros actores, como los padres de familia o las alcaldías.

Las investigaciones previas señalan que la modalidad ha sido aceptada por las juventudes y sus familias sobre todo por la cercanía, la gratuidad efectiva y la dinámica académica (Weiss, 2017b). También, se ha reconocido que la innovación didáctica son los libros de texto gratuitos, que no tienen otros bachilleratos, así como su modelo académico por campos disciplinares, la flexibilidad en las edades de acceso y los horarios (Weiss, 2017b; Estrada y Alejo, 2019).

La Secretaría de Educación Pública (SEP, 2018) señala que la creación del TBC en 2013 es parte de las transformaciones normativas, organizativas, operativas y curriculares en la EMS emprendidas un año después de que el Artículo $3^{\circ}$ Constitucional decretara su obligatoriedad. Cifras de la Dirección General de Bachillerato (DGB, 2019) dan cuenta del crecimiento exponencial de la modalidad, la cual de 253 centros educativos "piloto" en el ciclo 2013-2014 pasó a 3309 planteles en el ciclo escolar 2018-2019, lo que ha permitido el incremento y distribución de escuelas del nivel en las localidades más alejadas y vulneradas del territorio nacional.

A pesar de que se puede acreditar la igualdad en el reconocimiento del derecho a la educación en el país, el Instituto Nacional para la Evaluación de la Educación (INEE, 2019) apunta que aún persisten las brechas educativas por edad, nivel educativo y tipo de localidad. 
En el caso de las juventudes en localidades rurales, la asistencia decrece de $90.4 \%$ en el grupo de 12 a 14 años, a 63.2\% en el de 15 a 17 años (INEE, 2019, p. 16), lo que permite sostener que conforme avanza la edad disminuye la escolaridad, que media superior es el nivel de educación obligatoria que más excluye y que se mantiene la histórica relación entre exclusión educativa y jóvenes en contextos rurales.

Si bien, el TBC se creó para poblaciones que no eran atendidas por ningún subsistema y reducir la falta de equidad en la educación (Estrada y Alejo, 2019), aún es tarea pendiente de la política educativa y de la investigación conocer el punto de vista de quienes se escolarizan en este tipo educativo, cómo lo viven, lo significan, qué esperan y proponen. Dicha tarea parte del supuesto de que la escuela no es solo un espacio prescrito normativa 0 políticamente, sino una construcción social, cultural y pedagógica en la que jóvenes estudiantes participan, a la que dan y les da sentido. Considera también que, el paso por espacios educativos diferenciados produce efectos sobre las subjetividades del estudiantado en cuanto a sus expectativas y destino educativo, a partir de sus circunstancias de origen social-familiar, trayectoria educativa previa, aprovechamiento educativo y características sociodemográficas (Rodríguez Rocha, 2014).

La investigación se realizó en el estado de México donde se concentra el mayor número de Telebachilleratos Comunitarios del país (520) (DGB, 2019). El TBC del estudio se ubica en la periferia urbana de la región sur conformada, en su mayoría, por poblaciones rurales con alto y medio grado de marginación, y donde el 55\% de la población de 15 años y más tiene incompleta la educación básica, según datos del Consejo Nacional de Evaluación de la Política del Desarrollo Social (CONEVAL, 2012). De ahí que regionalmente tienen larga data las políticas educativas como el TBC para favorecer la educación obligatoria.

El artículo está organizado en cuatro apartados. El primero expone los referentes teóricos sobre subjetividad y narrativas escolares como procesos culturales y pedagógicos que se corresponden. Coloca una perspectiva sociocultural de juventud que discute su desacreditación a partir del acceso diferenciado a la educación y reposiciona sus subjetividades a través de la participación escolar. Posteriormente, presenta la perspectiva metodológica, aludiendo al taller de narrativas escolares como tecnología de una investigación dialógico-reflexiva, describe el grupo participante, las categorías empírico-teóricas, así como las líneas y dimensiones analíticas. En un tercer apartado se muestran los resultados articulados con los referentes teóricos de la investigación. Finalmente, algunas reflexiones conclusivas, que, en su carácter inacabado, permiten vislumbrar nuevas líneas de discusión y 
acciones pedagógicas en favor de políticas educativas y escuelas no solo para jóvenes, sino con jóvenes, en favor de su ejercicio del derecho a la educación y de renovadas comunidades educativas.

\section{Referentes teóricos}

El estudio se sustenta en una perspectiva teórica convergente para aproximarse a los signos de la subjetividad juvenil en las narrativas escolares que convocan a concepciones provenientes de distintos campos del saber: la antropología, la pedagogía crítica, así como la perspectiva sociocultural de juventud y escuela.

\subsection{Subjetividad y narrativas}

Desde una perspectiva antropológica la subjetividad remite a un sujeto entramado culturalmente que influye y es influenciado por el colectivo y el momento histórico que le toca vivir. Según Bárcena y Mèlich (2014), el entramado cultural está sostenido por procedimientos simbólicos, conceptos y construcciones que se hacen posibles mediante el lenguaje que, en tanto construcción social, permite comunicar lo que los sujetos, en este caso jóvenes estudiantes, sienten, creen, piensan y desean.

La subjetividad se configura en relaciones diversas de orden cultural que atraviesan situaciones en lo afectivo, educativo, social y político entre individuos, las cuales delinean acciones y voluntades recíprocas justo para hacerse sujetos. Es en relación con otros donde los y las jóvenes estudiantes heredan repertorios simbólicos que orientan su acción en el mundo, pero es la categoría de subjetividad la que recupera su capacidad creadora de significados y transformación. En el estudio, la subjetividad resulta un nodo analítico que permite articular los modos y códigos simbólicos relacionados con el vínculo juventud y escuela en el ámbito de las prácticas escolares y la política educativa.

Teóricamente, subjetividad y narrativa se articulan bajo la premisa del filósofo y antropólogo francés Ricoeur (2003) acerca de que la comprensión de sí sucede solo en el acto de narrar. Esta idea enfatiza la capacidad humana para la autocomprensión que necesariamente pasa por el acceso a la cultura en donde adquiere sentido nuestra acción que al ser narrada abre la posibilidad de constituirse en una experiencia reflexiva y por supuesto, en una historia digna de ser contada. La subjetividad constituye entonces una narrativa de sí, que conlleva siempre una interpretación, un acto de inteligibilidad, mediada por símbolos y signos, es decir, está mediatizada por la narración del mundo en el que se nace e interacciona. El trabajo se 
inscribe en lo que Bolívar, Domingo y Fernández denominan "el giro hermenéutico narrativo" (2001, p. 59) en las ciencias sociales y particularmente, en la investigación educativa; este se propone dar cuenta de los fenómenos educativos visibilizando a los sujetos en el marco de las estructuras sociales a partir de su voz y acción, resignificada en lo que aquí se ha denominado participación. Por tanto, en esta investigación, el enfoque narrativo no se limita a una metodología extractiva de información/análisis de datos, sino que constituye una perspectiva epistémico-metodológica para la construcción de conocimiento educativo, en donde la subjetividad constituye una condición fundante (Bolívar, 2010).

Bajo estos referentes las narrativas escolares juveniles se conceptualizan como producciones individuales/sociales que representan la experiencia vivida. A través de la palabra en diálogo emerge la subjetividad en tanto narrativa de sí en un contexto concreto que alimenta los referentes identitarios juveniles en el marco de las relaciones, construcciones y reconstrucciones personales, culturales y escolares.

Las narrativas escolares visibilizan la subjetividad juvenil en tanto sujeto de enunciación que pone en juego su producción simbólica para dar cuenta de su particular interpretación de la realidad, en este caso, a partir de su experiencia de acceso a la escolaridad y de los procesos en los que habita la escuela y es habitado por esta. Entre las funciones de simbolización que aparecen centralmente en este estudio están el lenguaje verbal, emociones e inscripciones juveniles en el contexto cultural local-global en que se produce la subjetividad, siempre dinámica, provisional, actualmente marcada por la incertidumbre y la precariedad económica.

Las narrativas escolares aparecen signadas por la experiencia social y escolar del sujeto juvenil que, en este caso fue interpelado colectivamente por las preguntas ¿quién soy-somos? ¿qué y para qué narrar lo que me-nos pasa en la escuela? Colocándose como agentes reflexivos con capacidad transformativa de su entorno escolar, es decir como sujetos de participación que dinamizan aspectos simbólicos propios de su ser, estar y aspirar desde la perspectiva de su condición juvenil capaces de producir nuevas narrativas escolares y sociales frente a condiciones que parecen determinadas.

La producción de dichas narrativas dinamiza sus códigos simbólicos y el principio de reflexividad, que según Bárcena y Mèlich alude a la capacidad para alterar el presente y también la capacidad de imaginar alternativas, de idear otras formas de ser, estar y actuar en el mundo. "En este juego dialéctico entre la reflexión y la imaginación de alternativas, 
reelaboramos, revaloramos, reevaluamos y reconfiguramos la cultura y a nosotros mismos dentro de ella" (2014, p. 107).

Las narrativas escolares dialécticamente están ligadas a la subjetividad juvenil en cuanto sientan las bases simbólicas necesarias para interpretar su mundo escolar y social, interpretándose a sí mismos, con los demás; de ahí la importancia del diálogo colectivo. Es en el encuentro con otros logos en tanto perspectivas, significados y sentidos que podemos pensarnos a nosotros mismos en interacción con otras subjetividades.

Bárcena y Mèlich (2014) señalan que "Como productores de acciones, somos agentes; pero también somos personajes, porque nuestras acciones tienen relación con nuestra biografía y con las historias que vivimos, con las cosas que nos ocurren" (p. 127), por eso las narrativas escolares se fundan en la experiencia, en eso que me-nos pasa, que hacemos que nos pase y que nos transforma (Larrosa, 2010).

La noción de experiencia permite establecer una relación entre narrativas escolares y la subjetivación en cuanto capacidad humana de hacer frente a los efectos de poder (Foucault, 1976); que en este trabajo reconoce la implicación de jóvenes en la producción de relaciones, interacciones, construcción de significados, elaboración de sentido e intercambio de experiencias en las que fluyen apreciaciones y valoraciones de la acción individual-colectiva para nuevos órdenes escolares y sociales. Al narrar verbalmente sus experiencias, visibilizan significados culturales, relaciones de poder, conflictos y sentidos que definen las acciones en un contexto local-regional, dejando al descubierto accesos precarizados a la escolaridad, así como la demanda por un renovado espacio escolar fundado en comunidades educativas dialógicas, participativas.

En ese sentido, las narrativas son portadoras de un valor pedagógico, en cuanto permiten detonar, desde las escuelas, procesos crítico-reflexivos acerca de las condiciones y relaciones sociales regionales en las que se encuentran inmersos los personajes involucrados en cada narración (Espinosa y Pons, 2017). El trabajo se adscribe a la propuesta de "configuración de currículos narrativos regionales que respondan a condiciones, procesos y relaciones in situ; reconociéndose el valor pedagógico de las narrativas escolares" (Espinosa y Pons, 2017, p. 7).

\subsection{Una perspectiva sociocultural de juventud y escuela}

Se acude a una perspectiva sociocultural latinoamericana de las juventudes, la cual se ha venido consolidando desde la década de los 90 para reflexionar, conceptualizar y 
problematizar a la juventud como una construcción histórico-social situada (Reguillo, 2010, 2014; Medina, 2010; Valenzuela, 2015) que define modos diversos de ser joven en los complejos y contradictorios escenarios sociales de cada época de acuerdo a los valores y códigos culturales, económicos, educativos en torno a la edad, el origen social, el género y pertenencias que configuran múltiples maneras de entender y actuar en la realidad. Según Reguillo la condición juvenil refiere a

(...) un conjunto multidimensional de formas particulares, diferenciadas y culturalmente "acordadas" que otorgan, definen, marcan, establecen límites y parámetros a la experiencia subjetiva y social de las/los jóvenes. La condición se refiere a posiciones, categorías, clases, situaciones, prácticas, autorizaciones, prescripciones y proscripciones que se asumen como "naturales" al orden vigente y tienden a naturalizarse como "propias" o inherentes a esta franja etaria. (2010, p. 401)

Dado que hay diversas maneras de ser joven derivadas de la transformación social, cultural y comunicacional, así como de una desigual distribución de los capitales; esta investigación puso la mirada en los elementos contextuales que tienen efectos diversos en la condición juvenil a través de accesos diferenciados a la escolaridad; dichos procesos instalan diferencias en el modo en que la población de jóvenes se mira a sí misma y se relaciona con otros dentro-fuera del espacio escolar.

Las narrativas escolares evidencian dichas diferencias y sitúan la reflexión en torno a procesos de estigmatización que desacreditan a ciertas juventudes (Valenzuela, 2015) como aquellas de los contextos marginales y rurales históricamente precarizados cuyas condiciones se han desplazado a los sujetos empobrecidos económica, simbólica y políticamente a través de estereotipos urbano céntricos con estilos de vida y de consumo excluyentes promovidos por el neoliberalismo; estos estigmas también ha legitimado el acceso a canales de escolarización diferenciados que empobrecen la biografía.

De acuerdo con Valenzuela las identidades juveniles estigmatizadas funcionan como argumento que permite

la constante descalificación, desacreditación y proscripción a partir de la fuerza inicial del estigma, que se produce y reproduce desde ámbitos institucionalizados y se (re) crea a través de los procesos de estructuración social y de los imaginarios sociales dominantes. (2015, p. 20) 
Por lo general, los estigmas se sostienen en prejuicios, racismos, discriminaciones que funcionan como sistemas de clasificación social. Frente a los descréditos juveniles, las narrativas escolares constituyen un contra-relato a discursos que, incluso a través de las políticas educativas, descapitalizan a las juventudes ocultando la condición estructural que históricamente los ha colocado en itinerarios fragmentados de escolaridad. En este sentido, las narrativas escolares hacen eco a las voces, las experiencias y acciones que emergen desde su experiencia para denunciar las desigualdades en el acceso a la escolaridad. Así también visibiliza subjetividades juveniles que desafían con su palabra y acción enunciaciones desacreditadoras y normativas para gestionar escuelas participativas que escuchen su sentir, saberes tradicionales, responsabilidades y luchas comunitarias, propuestas y apuestas.

Desde una perspectiva simbólica, la escuela se conceptualiza como un cruce espaciotemporal en la constitución de la condición y la subjetividad juvenil; funciona como frontera (Duschatzky, 2008), pasaje de reconocimiento social y de socialidades más allá de lo doméstico, así como de nuevos discursos y conocimientos. De manera antinómica, potencia subjetividades, pero también marca diferencias y produce descréditos a través de un orden escolar excluyente en donde sus dinámicas, contenidos y normas son componentes de expulsión, sobre todo para aquellos que no miran en la escuela dividendos inmediatos que consiguen en la informalidad o la delincuencia organizada.

Lo que el estudiantado piensa y dice sobre la escuela evidencia que el acceso a la escolarización no garantiza el derecho a aprender, ni tampoco la oportunidad de romper las limitantes que impone el origen social; de ahí que la valoración sea una construcción siempre situada, encarnada. Así el ejercicio del derecho a la educación se coloca bajo la perspectiva de un paradigma crítico que a la par de la cobertura, favorezca espacios escolares equitativos, participativos y potenciadores de la experiencia social (Magendzo, 2001).

Desde esta mirada la escuela evoca sentido porque opera como un campo de posibilidad, como horizonte. Más allá de prescripciones políticas o pedagógicas, se sitúa en el terreno de la interacción, la vivencia, la experiencia, la subjetividad; es un espacio en el que se configuran y reconfiguran valores y discursos en interacciones de diverso orden (generacionales, culturales, cognitivas, afectivas, políticas) que abren un cauce de sentidos para la construcción del inédito viable al que aludía Freire (1970) y que en este caso, convoca a la imaginería juvenil para reinventar la escuela en el curso de sus experiencias, interacciones y corresponsabilidades motivadas por la noción de comunidades educativas, que convocan a la construcción de lo común desde lo diverso. 


\subsection{Revisión de literatura}

La literatura actual en el campo de escuela y juventud evidencia un creciente interés por investigar a la juventud en tanto estudiante. En el estado de conocimiento Estudiantes, Maestros y Académicos en la Investigación Educativa (Saucedo, Guzmán, Sandoval y Galaz, 2013) del Consejo Mexicano de Investigación Educativa (COMIE), Guzmán y Saucedo (2013) apuntan que en la década de 2002 a 2012 se registró un aumento significativo en la investigación de las juventudes en tanto sujetos educativos y se configuró un campo caracterizado por la diversidad temática, disciplinaria y metodológica, además de la profundización en los análisis en los distintos niveles. No obstante, en lo que va de la última década aún son escasos los trabajos ocupados en el Telebachillerato Comunitario.

En el último congreso del COMIE 2019, en el Área Temática Sujetos de la Educación, destaca la investigación de López y Reyes (2019) sobre las trayectorias sociales de jóvenes que abandonaron el TBC considerando que las condiciones de su funcionamiento y el reconocimiento de que esta opción escolar difícilmente garantiza condiciones para recorridos escolares exitosos; empero, los resultados muestran que el TBC representa una oportunidad de formación en relación con las habilidades prácticas; así como valores que constituyen mapas para orientar las acciones de los jóvenes, sustentadas en el trabajo colectivo, la interacción, el conocimiento y valoración de sus comunidades.

Otros estudios muestran que la modalidad no ha logrado consolidarse ni en cantidad, ni en calidad para lograr la equidad educativa (Estrada y Alejo, 2019). Así también hay investigaciones que han abordado las condiciones de desarrollo institucional y la relación conflictiva y estratégica con las telesecundarias y las comunidades. Al respecto, destaca el estudio de Weiss (2017b) ocupado en la evaluación de las estructuras institucionales e innovación del curriculum, así como de las tensiones entre el modelo y su operación. Por su parte Guzmán y Padilla (2017) han centrado la mirada en la perspectiva de la eficacia y la mejora escolar en el nivel, escuela y aula. El estudio de Escamilla (2019) resulta relevante pues se desarrolla también en la región sur del estado de México a través de una investigación en diálogo e interacción con jóvenes para desplazar la mirada de un modelo de cobertura de la educación media superior hacia lo que denomina un modelo socio civil desde una política de juventud.

En el Instituto Superior de Ciencias de la Educación del Estado de México (ISCEEM) son referenciales investigaciones y tesis doctorales que han puesto la mirada en procesos que comprometen el pleno ejercicio del derecho a la educación a través de la exclusión escolar 
interna (Hernández, López y Salgado, 2012), marcas inclusoras y exclusoras (Jiménez, 2019) y claroscuros de inclusión/exclusión (Sánchez Morales, 2019) con juventudes en contextos urbano marginales y rurales en el nivel medio superior, advirtiendo una exclusión velada que se oculta bajo precarizantes y discriminatorios procesos de inclusión educativa, dentro de los que se destacan experiencias de agencialidad y subjetivación juvenil.

Particularmente, la investigación que se presenta sitúa su aporte tanto en la producción de conocimiento e incidencia en las prácticas educativas en una modalidad en expansión y con la propuesta de avanzar en una investigación educativa no solo acerca de, sino con sujetos juveniles en encuentros epistémico-pedagógicos, en este caso a través del diálogo y la producción de narrativas escolares que convocan a la subjetividad para comprender cómo se miran y miran su entorno inmediato desde la escuela, cómo la habitan, qué los con-mueve, cómo la imaginan; asumiendo que la participación juvenil potencia renovados órdenes y sentidos del espacio-tiempo escolar como una construcción de lo público y lo común.

\section{Metodología}

La investigación se desarrolló en el periodo noviembre de 2018-2020 a partir de criterios teórico-empíricos desde donde se adscribe a la tradición comprensiva interpretativa de la investigación cualitativa (Tójar, 2011) y a las metodologías dialógicas (Corona y Kaltmeier, 2012) y narrativas (Bolívar, 2010; Bárcena y Mélich, 2014;) con las que se busca captar aspectos subjetivos y objetivos de la experiencia escolar y social del estudiantado.

\subsection{Enfoque}

Se adscribe a un enfoque cualitativo-interpretativo que ha pugnado por la captación de sentido de las acciones sociales en su contexto (Weber, 1971) y las formas histórico-culturales en que este se ha producido y produce. El trabajo incorpora la narrativa como procedimiento para construir saber educativo (Bolívar, 2010; Bárcena y Mèlich, 2014) potenciando la participación de jóvenes a través de diálogos horizontales (Corona y Kaltmeier, 2012) a partir del reconocimiento de sujetos que habitan la escuela y la investigación. En el campo de la educación, la narrativa "es una forma de construir realidad, de ordenar la experiencia, apropiarse de ella y de sus significados particulares y colectivos" (Bolívar, 2010 p. 204).

Con un alcance descriptivo-interpretativo las narrativas escolares producidas en el diálogo colectivo visibilizaron la dimensión subjetiva y objetiva del estudiantado a través del 
contar sus vivencias en el TBC; al participar reflexionaban su decir/accionar dejando abierta la posibilidad de modificar el rumbo de su acción desde el presente.

\subsection{Diseño y unidades de análisis}

El diseño de investigación se fundó en una estrategia dialógica y de interacción cultural y pedagógica a través de la investigación tallerista (Hernández, Salgado, Benítez y Velasco, 2020) fundada en interacciones y diálogos con diversos agentes educativos en la escuela y sus comunidades desde una perspectiva de acción participativa y también sentipensante (Borda, 2007). La interacción aquí supuso una incidencia recíproca, una corresponsabilidad ética, mediada por visiones de la vida y la escuela a través de los códigos simbólicos e intergeneracionales, que la hacen siempre contingente y que no exime relaciones de poder, particularmente en la condición de joven estudiante con respecto a la figura adulta del profesorado, la investigadora o diseñadores de política educativa.

La investigación tallerista con jóvenes en las escuelas constituyó así un modo particular de acción participativa para favorecer un diseño de investigación habitado por las necesidades y las decisiones de quienes colaboran en esta, articulando exigencias del problema de estudio desde el contexto y sujetos concretos a la luz de la teoría y el dinamismo de la realidad. En este sentido, alude a una práctica epistémica, producto de la construcción sostenida en la participación y la interpretación, así también alude a una práctica pedagógica en tanto convoca al reconocimiento y construcción de la diversidad, la convivencia y la democracia.

Bajo la lógica planteada, el diseño de investigación tuvo como punto de partida la interacción inicialmente con la docente encargada y el estudiantado en un Telebachillerato Comunitario que fue seleccionado bajo los siguientes criterios:

- Acreditar la primera generación de egresados del TBC en la región

- Ubicarse en una zona conurbada, rodeada de localidades rurales en las que se ubica el $15 \%$ de los Telebachilleratos Comunitarios de la entidad

- Condiciones de acceso al plantel

Como resultado de las interacciones y diálogos con la docente acerca de las problemáticas y las necesidades en el TBC se acordó desarrollar el taller Narrativas de mi experiencia escolar. Emociones, relaciones y aprendizajes; el cual inicialmente respondió a la demanda de la docente de incidir en el ámbito socioemocional que actualmente es un transversal en la curricula de Educación Media Superior en el país; el taller correspondió con 
el objetivo de la investigación de favorecer escuelas participativas y procesos pedagógicos reflexivos.

La participación del estudiantado fue consensuada mediante un oficio que estipuló el título y registro institucional de la investigación, así como el objetivo, la justificación, las temáticas, las actividades, el lugar y las fechas del taller. Suscribió la asistencia voluntaria y el uso de la información con fines estrictamente de investigación conservando el anonimato de los participantes y del plantel.

Según la propuesta de la docente responsable del TBC, el taller se presentó y convocó al grupo del sexto semestre, el cual accedió a participar con la convicción de que -decían- "son importantes más espacios para platicar, que sepan qué sentimos, qué nos pasa en la escuela" (Voces colectivas, Taller TBC, 2018). Tuvo una duración de 10 horas, entre el 5 y el 9 de noviembre de $2018^{3}$. Las sesiones se desarrollaron en las últimas dos, de cuatro horas que en promedio asisten a clases, en tiempos que la profesora responsable ocupó en lo administrativo. En las cinco sesiones del taller consintió participar la totalidad del grupo conformado por 23 jóvenes (13 mujeres y 10 varones) con trayectorias sociales y escolares diversas, la mayoría eran jóvenes que trabajan y estudian, vivían en pareja, eran padres o madres de familia que incluso asistían a clases con sus hijos. Varios habían llegado al plantel expulsados de otras escuelas o antes se hallaban en condición de rezago educativo y su edad oscilaba entre los 17 y 21 años.

\subsection{Técnicas de recolección}

El taller de narrativas escolares se distanció de un protocolo de aplicación de las técnicas de investigación, para situarse como una tecnología 4 diseñada desde las demandas, lógicas e intencionalidades de los sujetos partícipes de la investigación valorado como un dispositivo de trabajo con grupos, que permite la activación de un proceso pedagógico que integra teoría y práctica, destacando el protagonismo de los participantes, el diálogo de saberes y la producción colectiva de aprendizajes, "operando una transformación en las personas participantes y en la situación de partida" (Cano, 2012, p. 33).

\footnotetext{
${ }^{3}$ El taller dio continuidad a una actividad de extensión educativa institucional desarrollada en el mes de marzo de 2018 por el CA para favorecer interacciones educativas equitativas y participativas en escuelas secundarias y de media superior en contextos desfavorecidos.

${ }^{4}$ La categoría llama a reconocer las lógicas e intencionalidades particulares y contextualizadas de las técnicas de investigación, para revalorar su papel mediador entre el campo y los sujetos que participan en la investigación.
} 
El taller adquirió la forma de un diálogo colectivo en el que el estudiantado compartió narrativas verbalizadas acerca de episodios significativos de su experiencia escolar generando juicios propios sobre dichas situaciones, en algunos casos repensando o proponiendo alternativas con los otros, en ejercicios de construcción retrospectiva, de expectativas y perspectivas futuras.

La Tabla 1 muestra los ejes y preguntas que orientaron el desarrollo del taller:

Tabla 1. Taller Narrativas de mi experiencia escolar. Emociones, relaciones y aprendizajes Ejes de diálogo Preguntas para la reflexión colectiva

1. Soy, siento y convivo

2. Mis interacciones en la escuela y comunidad

3. Experiencia escolar $y$ derecho a la educación

4. Reinventar la escuela ¿Quién soy? ¿Cómo me miro a mí mismo? ¿Cómo me siento en la escuela, por qué? ¿Qué es lo que más recuerdo en mi paso por el TBC?¿Qué quisiera olvidar, por qué?

¿Cómo valoro mis relaciones con compañeros, amigos, profesores y padres? ¿Qué es lo que más me gusta hacer en la escuela? ¿Qué es lo que menos gusta y por qué? ¿Cuál es mi espacio favorito?¿Qué responsabilidades tengo con la escuela y mi comunidad?

¿Qué significa tener derecho a la educación? ¿Cómo ejerzo este derecho?¿Cómo participo en la definición de la vida escolar?¿Para qué me sirve la escuela?¿Cómo valoraría mi experiencia escolar en el TBC?

¿Cómo me gustaría que fuera la escuela? ¿Qué le cambiaría? ¿Qué propondría para construir una escuela para y con jóvenes?

Fuente: Elaboración propia con base en la estructura del taller (2020).

Las preguntas dieron lugar a la producción de narrativas escolares en un intercambio de experiencias que se colocaron como ejes de diálogo enmarcados en una reflexividad individual-colectiva acerca de quiénes son-somos y qué signa sus itinerarios escolares, cómo interactúan con los otros y cuál es su sentir en el espacio escolar, sus vivencias, afectaciones y tensiones, qué proponen para reinventar la escuela y sus estancias ahí, qué escuela imaginan. Las voces, las experiencias y su reflexión surgieron de la disposición al diálogo en una pluralidad de tonos, matices y gestos.

Las sesiones fueron videograbadas y después transcritas; según Knobel y Lankshear (2001) la preparación de datos hablados para el análisis involucra escribir estos en un texto para su sistematización, análisis e interpretación que da lugar a categorías temáticas basadas en regularidades, aspectos destacables, elementos comunes y divergentes que prefiguraron las líneas analíticas. Debe advertirse que la transcripción difícilmente resulta neutral pues está determinado por las decisiones, objetivos y modos de escritura de quien investiga (Knobel y Lankshear, 2001). Así, las voces juveniles fueron vueltas textos polisémicos insumo para el 
acto interpretativo que consistió en colocarlos en su contexto para dar cuenta de su significado, intencionalidad y recontextualización.

\subsection{Procesamiento de análisis}

Los tópicos que orientaron el diálogo permitieron una lectura ordenada y global de los textos para establecer relaciones e inferencias presentes en la interpretación. Para la sistematización del corpus empírico se diseñó artesanalmente una sábana de datos, organizada a partir de las preguntas de investigación, los ejes de diálogo en el taller, las voces juveniles y los referentes teóricos.

La sistematización de empíricos se realizó con base en las siguientes líneas analíticas:

- Acceso excluyente a la escolaridad

- Subjetividades juveniles desacreditadas y con-movidas

- El derecho a participar

- Reglamentos y organización escolar

- Lucha por el reconocimiento

- Reinventar la escuela, hacia otras comunidades educativas

Las líneas abrieron cuatro dimensiones de análisis articuladas y transversales en la interpretación de las narrativas escolares; las cuales recuperaron los cuatro discursos en los que, según Bárcena, se asienta la idea de educación como práctica reflexiva (Bárcena, 2005) y son las siguientes:

- dimensión normativa que coloca las prescripciones jurídicas, en este caso, en torno a la obligatoriedad de la educación media superior, así como la política educativa del TBC, su Documento Base (SEP-DGB, 2018) y los reglamentos escolares que prefiguran a la población a la que se direcciona, así como sus prácticas.

- dimensión contextual como cruces espacio-temporales en que la normatividad y política educativa son resignficadas desde la cotidianidad de los sujetos, se considera aquí su condición juvenil y los códigos simbólicos en sus itinerarios escolares, lo que los signa y con-mueve en modos diversos de acceso a la escolaridad.

- dimensión interaccional que da lugar a las relaciones, vínculos, acciones, emociones y solidaridades, que en esta investigación aluden a talantes de comunidades educativas fundadas en un ideal ético (Bárcena, 2005). 
- dimensión político deliberativa que encarna la experiencia en la participación y reconocimiento, considerados principios del ejercicio del derecho a lo educación, procuran cambiar un orden escolar dado en términos de valor para dar lugar a acontecimientos que lo irrumpen y construir experiencia que no es posible prefabricar.

\section{Resultados}

La experiencia dialogal (Bárcena, 2005) basada en la reflexión personal/colectiva con jóvenes estudiantes en el taller reveló que su experiencia en el TBC, en una zona conurbada del sur mexiquense, signa su subjetividad a través del acceso excluyente a la escolaridad en procesos históricos de precarización económica y simbólica que los desacredita. No obstante, las narrativas escolares también sitúan acontecimientos en donde las subjetividades juveniles se con-mueven, accionan, participan para crear alternativas de ser y actuar. Según Bárcena en el campo de la educación "la reflexión conlleva la connotación de hacer deliberaciones, elecciones, tomas decisiones sobre cursos alternativos de acción" (2005, p. 147) que, en este caso, hicieron posible sentir/pensar la escuela con los sujetos que la habitan a partir de las líneas analíticas que se esbozan a continuación.

\subsection{Acceso excluyente a la escolaridad}

El Documento Base 2018 adopción del Modelo Educativo para la Educación Obligatoria en el Telebachillerato Comunitario (SEP-DGB, 2018) apunta que es una modalidad escolarizada, presencial, preferentemente dirigida a poblaciones en contextos rurales, de marginalidad, o bien, aquellas que teniendo otras condiciones no cuentan con la educación media superior satisfecha. Al respecto, en su narrar el estudiantado la valoró como "una oportunidad educativa y una opción para las personas que de verdad tienen ganas de estudiar, pero que no tienen demasiados recursos" (Estudiante mujer, 21 años, Taller TBC, 2018).

Enfatizaban la flexibilidad, gratuidad efectiva y la dinámica académica, así también subrayaban su condición de extra edad a la que resignificaban en la posibilidad de recuperar sus trayectorias escolares. Asimismo, resaltaban un horario vespertino que les favorece para trabajar $\mathrm{o}$ atender a sus hijos y quehaceres por la mañana; empero, evidenciaron también que el Telebachillerato Comunitario "aparece no sólo como una oferta que acerca la educación a aquellos lugares que no tienen otra opción, sino como la oferta que atiende a los que ya no pueden ser absorbidos por otros espacios" (Weiss, 2017b, p. 13) es el caso de jóvenes que han tenido trayectorias escolares "irregulares" o que no cuentan con los créditos académicos 
y simbólicos para ingresar a otras escuelas. Recurrentemente relacionaron la escasez de recursos económicos e itinerarios sociales y escolares fragmentados como justificación de su acceso a esta modalidad educativa.

Por lo general, el TBC no es su primera opción, apuntaron: "esta escuela no la tenía ni contemplada, fue mi jefa ${ }^{5}$ la que eligió esta escuela" (Estudiante varón, 19 años, Taller TBC, 2018), "Mi primera opción fue la Normal... pero allá nomás estuve un semestre por problemas con un maestro" (Estudiante varón, 20 años, Taller TBC, 2018). En la mayoría de los casos, el TBC no es la opción que eligen, sino la que les queda; en una doble acepción, confeccionada a la medida como política pública para sujetos y contextos empobrecidos económica y simbólicamente.

Históricamente, las juventudes lidian social, cultural y subjetivamente con marcas de desigualdad socioeconómica y escolar que les vulneran con categorías normativas (Reguillo, 2014) de política educativa que perfilan, estigmatizan y definen sujetos arbitrariamente e invisibilizan la dimensión estructural en la que se traman los accesos diferenciados a la educación. Al respecto, comentaron:

No nos toman en cuenta igual que a todos, nos excluyen, a veces nosotros no siempre tenemos recursos para el uniforme, pagar la colegiatura, la comida, los traslados... a veces nos dicen que si no nos gusta esta escuela podemos buscar por otra parte, pero los maestros no se dan cuenta de las oportunidades que no tenemos nosotros. (Estudiante varón, 17 años, Taller TBC, 2018)

Por lo regular, ingresan al TBC quienes han acumulado desventajas académicas por rezago educativo, reprobación o disciplina; de ahí que la modalidad no escape a procesos clasificatorios y desacreditadores que el estudiantado significa y subjetiva en expresiones unísonas como "nuestra escuela no vale...nosotros somos los más abatidos... excluidos... los más pobres...no nos reconocen como una institución, como una prepa oficial, porque es telebachillerato... se burlan del nombre..." (Voces colectivas, Taller TBC, 2018).

Las expresiones destacan una condición escolar desigual en relación con otras opciones, manifestaron "[aquí] nos excluyen y al decir nos excluyen me refiero de las otras instituciones, de la sociedad y del gobierno" (Estudiante varón, 17 años, Taller TBC, 2018). Datos del INEE (2019) señalan que los Telebachilleratos Comunitarios en México presentan

\footnotetext{
${ }^{5}$ La expresión refiere a la madre.
} 
serios problemas de infraestructura, el $85 \%$ de los planteles no cuenta con bibliotecas, ni aulas de cómputo. Otras carencias importantes son los salones y los laboratorios de ciencias en el 99\% de los casos; no obstante, algunos, con sus propios medios y gestiones de las autoridades escolares, locales y de la comunidad los han ido construyendo.

El estudiantado enfatizó en que "para ejercer el derecho a la educación hacen falta más maestros" (Estudiante varón, 17 años, Taller TBC, 2018). El TBC tiene una estructura mínima de personal que contribuye a optimizar los recursos que no necesariamente corresponden con las expectativas y las demandas estudiantiles. La modalidad se ha caracterizado por una planta de profesionistas jóvenes que inician su experiencia docente. Son tres profesores los que atienden las asignaturas del plan de estudios por área disciplinar (Matemáticas y Ciencias Experimentales; Ciencias Sociales y Humanidades y; Administración y Comunicación) con un mapa curricular modular. En el TBC de estudio la impartición de contenidos se desarrolla en 4 horas diarias de clase. Una de tres docentes tiene también la función administrativa, lo que, expresó el estudiantado, "impide terminar los contenidos porque cuando la responsable no viene, por su función, se pierden hasta tres materias (Estudiante varón, 17 años, Taller TBC, 2018).

Desde un paradigma crítico y de educación en derechos humanos, Magendzo advierte que el derecho a la educación que ofrece un sistema educativo es violentado cuando "...la calidad del servicio que entrega es deficiente, inconducente y poco pertinente" (2001, p. 75). Dicha situación menoscaba los principios fundamentales que suponen la entrega de servicios no solo universales, sino equitativos y suficientes.

Si bien, el TBC favorece la obligatoriedad constitucional de la educación media superior al atender la cobertura y la gratuidad queda pendiente el acceso inclusivo a la educación, que, en tanto derecho, no debe ser discriminatorio, sino procurar una educación en la que todos y todas tengan las mismas oportunidades.

\subsection{Subjetividades juveniles desacreditadas y con-movidas}

Resulta relevante que en las narrativas escolares las personas jóvenes participantes se asumieran como "excluidos y abatidos" (Voces colectivas, Taller TBC, 2018) haciendo evidente una encarnación de descréditos en la que se traman subjetividades juveniles a través de marcas y estereotipos que funcionan como sistemas de clasificación y violencia social (Valenzuela, 2015). Al respecto, esta población de jóvenes manifestó que en la calle o en el transporte público son señalados por estudiar en el TBC "porque aquí vienen los más pobres, 
indigentes, vagos, drogadictos, los que no quisieron en otras escuelas..." (Estudiante mujer, 19 años, Taller TBC, 2018).

Los estereotipos se refuerzan con las sedimentaciones discursivas de perfiles de población prioritaria y la implementación precaria de la política educativa, lo que da lugar a la configuración de subjetividades juveniles desacreditadas (Valenzuela, 2015; Salgado, 2020) y condiciones precarias-precarizantes en lo material y simbólico. La política educativa trabaja con categorías normativas de la juventud (Reguillo, 2014), como lo marginal y rural, que no solo adjetivan, sino que llegan a sustantivar la condición juvenil desconociendo los procesos históricos, simbólicos y políticos en que se constituye.

Ante ese vacío, las narrativas escolares visibilizan trayectorias y experiencias que posibilitan reconocer distintos modos de ser joven dentro del propio ámbito escolar, estas diferencias guardan relación con los lugares y protagonismos familiares, comunitarios y dentro de la institución. Las narrativas escolares están signadas por su experiencia juvenil como padres-madres de familia, la doble tarea de estudiar y trabajar, la migración o el no "encajar en otras escuelas" que fractura y redefine su itinerario y proyecto escolar.

Las narrativas escolares están atravesadas por el pasado-presente-futuro a través de itinerarios de vida que, en opinión de una estudiante, encuentran en el TBC "una oportunidad valiosa para retomar los estudios, tener mejores oportunidades de empleo o incluso ser el orgullo de los hijos o los padres" (Estudiante mujer, 21 años, Taller TBC, 2018). Al mismo tiempo, las narrativas escolares revelan subjetividades juveniles marcadas por una cadena de desventajas económicas y simbólicas que conducen a la precariedad social y escolar.

Las narrativas escolares constituyen un ejercicio reflexivo y problematizador de categorías desacreditadoras de las juventudes y una denuncia de desiguales accesos a la escolaridad. Así también, visibilizan subjetividades con-movidas (Salgado, 2019) que desafían los descréditos con su palabra y propuestas para gestionar escuelas participativas.

Las subjetividades con-movidas se indignan y dan pie al inédito viable (Freire, 1970) con su participación y propuestas para una escuela fundada en la escucha y el diálogo, en la que enfatizan la posibilidad de procesos de aprendizaje basados en relaciones afectivas y lúdicas. Una escuela en la que sean considerados en la definición de las normas que, afirmaron, "son para nosotros, pero en las que no nos toman en cuenta (Estudiante varón, 19 años, Taller TBC, 2018).

Sin duda, otros órdenes escolares posibles que emergen desde su voz, experiencias y expectativas, entre subjetividades juveniles que se dinamizan bajo la convicción de que la 
escuela se puede reinventar en común y en donde se puede ir siendo de otro modo, irrumpiendo el orden tradicionalmente instituido.

Es así como la experiencia escolar se dispone por acontecimientos situados espacial y temporalmente en subjetividades narradas que se con-mueven en el marco de historias y lecturas de poder mientras se ponen en relación e interacción con otras subjetividades para imaginar alternativas de ser, actuar y educar en la escuela.

Entre subjetividades con-movidas por el amor, el enojo y la frustración del descrédito y no participar en la definición de la vida escolar, las juventudes fundan el motor de su acción escolar y social. Así, los y las jóvenes deciden continuar estudiando por sus hijosque los motivan a superarse; o por el deseo de encontrarse con sus grandes amistades. Las subjetividades juveniles son con-movidas por vínculos solidarios diversos, destacaron las tutorías entre pares en las que revisan temas académicos y se dan consejos; además de la solidaridad de su profesora que les permite estar con sus hijos en la clase cuando no hay quien los atienda.

Expresaron con-moverse también por la tristeza relacionada con ausencias de los padres debido al abandono o la migración; así como "sentir el miedo a no poder terminar la escuela cuando a veces no hay de otra" (Estudiante mujer, 21 años, Taller TBC, 2018).

Las subjetividades juveniles emergieron en cruces de poder, un poder siempre incompleto en su dominación y que deja lugar a recorridos concretos y diferentes en una red abierta de relaciones, acciones y posibilidad que reinventa la vida con los otros, convocando a relaciones intersubjetivas (Berlanga, 2018).

\subsection{El derecho a participar}

Esta línea de análisis visibilizó modos de apropiación y resignificación juvenil de la escuela. Medina (2010) enfatiza la manera en que la juventud se apropia de códigos de las culturas institucionales creándolos y recreándolos con sus pares a la luz de su sentido, intereses y proyectos a futuro. Esta reapropiación del espacio institucional conlleva modos de participación juvenil motivados por principios como la libertad, la igualdad, la solidaridad, la responsabilidad, la autonomía crítica y la justicia social.

La población de jóvenes estudiantes colocó sobre manera dos aspectos que orientan la vida en común en la institución escolar: la participación en las normas y las luchas por el reconocimiento, estas ponen en el análisis la participación en la toma de decisiones sobre su propio actuar, sus modos de ser y de estar en la escuela. En sus narrativas, valoraron la 
escuela como un espacio para el aprendizaje y la formación para lograr un mejor trabajo; pero en el que dijeron, difícilmente se les escucha y deciden; al respecto señalaban "el reglamento lo que quiere es que los jóvenes salgan como masa, con una sola mente, y debe ser que cada persona lleva su propio ideal y decisiones" (Estudiante varón, 18 años, Taller TBC, 2018).

Expresaron su inconformidad no estrictamente por las reglas, sino por los procesos arbitrarios y excluyentes que los invisibiliza y niega su derecho a participar en la definición de la convivencia dentro de la institución (Salgado, 2019). Uno de los jóvenes apuntó:

El derecho a la educación no es respetado para todos, todos tenemos derecho a la educación, pero en las instituciones por medio de sus reglas privan de ese derecho a muchas personas, tal vez porque no tiene el recurso para el uniforme, para una inscripción, los traslados, la comida, y nada de eso es tomado en cuenta, solamente te dicen no puedes pagar el uniforme, la comida, vete a otra escuela... o simplemente no te parece el reglamento vete a otra escuela. (Estudiante varón, 17 años, Taller TBC, 2018)

Resulta paradójico el sentido de lo normativo, pues mientras el derecho a la educación de las juventudes tiene como un fundamento la participación, los reglamentos escolares, en su mayoría, son establecidos al margen de sus voces, necesidades, códigos simbólicos y condiciones sociales. Si bien, las normas median las interacciones en la escuela estas son discutibles cuando, bajo una supuesta adherencia institucional y arbitrariedad de posiciones, constituyen un derecho desigual a la educación. De acuerdo con Honnet (1997), el reconocimiento de la identidad individual, posibilitada por la interacción con otros, tiende a una demanda y lucha por ampliar y ejercer derechos; por tanto, el reconocimiento es activo, cooperativo y social (Magendzo, 2001).

Las narrativas escolares anudan experiencias, demandas y propuestas que entraman una crítica social a las condiciones y prácticas en que día a día van configurando su condición de escuela. Sus voces resultan fundantes del derecho a la educación, por cuanto sujetos que son capaces de cuestionar la realidad social, las inequidades, el poder y las posibilidades de otro orden.

El descrédito, emociones y exclusión escolar que signan las narrativas escolares de las juventudes motiva a la reflexión de la experiencia cual punto de partida de acciones que les permitan crear perspectivas y posibilidades distintas de colocarse en la institución escolar y el mundo como subjetividades que se indignan, conmueven y alzan la voz para ser reconocidos; 
en este sentido, un joven apuntó: "Al fin y al cabo como vengas, tatuado o greñudo como quieras, no afecta tu aprendizaje" (Estudiante de TBC, varón, 19 años, Taller TBC, 2018).

La participación juvenil constituye una demanda encarnada por espacios escolares incluyentes, donde resulta insuficiente el estar dentro, implica el reconocimiento de condiciones inequitativas y sujetos diversos en una lucha por ampliar y ejercer derechos.

En la participación se traman subjetividades juveniles con-movidas, que también son emancipadoras. De acuerdo con Berlanga (2018) estas subjetividades potencian su dignidad humana y resignifican lo político al desmarcarse de discursos excluyentes, desafiar lo vivido y construir nuevas experiencias y proyecciones de sí mismo, en cuerpo, razón y emoción puestos en la producción de lenguajes y experiencias. Las subjetividades juveniles se constituyen también en práctica política y pedagógica de subjetivación, la cual es una forma de autoreconocimiento, un ejercicio reflexivo con otros en el que se aprende y ejerce el derecho a pronunciarse a sí mismos.

Las subjetividades juveniles desacreditadas y con-movidas en el Telebachillerato Comunitario convocan a la reflexión de la experiencia individual-social a través de su narrativa cual punto de partida de acciones que les permitan crear perspectivas y posibilidades distintas de colocarse como poseedores de logos en la política educativa, así como de otros modos de relación, locus escolares y proyectos.

\subsection{Reinventar la escuela. Hacia otras comunidades educativas}

Las juventudes con su palabra y disentir participan en un discontinuo reinventar la escuela, sus voces y experiencias irrumpen y filtran el silencio para crear nuevas o renovadas comunidades educativas fundadas en la horizontalidad enunciativa que convoca a la alteridad y al inédito viable que con-mueve. En la educación, la narrativa "Es un espacio que se nos abre a la participación y a la comunicación con el mundo, para ganar en experiencia humana" (Bárcena y Mèlich, 2014, p. 132).

Dicha posibilidad tiene cabida en el reflexionar dialógico de la experiencia, en el narrar y convivir con los otros, en lo común/diverso que potencia la idea de lo humano, pues como decía un estudiante en el diálogo colectivo: "Antes de ser estudiante soy humano con derechos" (Estudiante varón, 19 años, Taller TBC 2018).

Las narrativas juveniles convocadas colectivamente en la escuela llaman a recuperar el sentido comunitario de esta, pues "son las historias y relatos comunes, transmitidos por 
tradiciones culturales las que crean comunidades de sentido y creencias, en las que se inscribe cada persona" (Bolívar, Domingo y Fernández, 2001, p. 94).

Las narrativas escolares convocan a renovadas relaciones intergeneracionales, del saber e interculturales, fundadas en el reconocimiento, la participación y la solidaridad. Si bien, la universalización de la educación media superior exige un marco curricular común, homologado con competencias fundamentales para la vida; desde una perspectiva éticopolítica el ejercicio del derecho a la educación también implica el reconocimiento a la diversidad y a la construcción de experiencias y horizontes que potencien las subjetividades juveniles.

\section{Conclusiones}

A partir de las voces, experiencias, reflexiones y propuestas de jóvenes estudiantes que participaron en la investigación, se visibilizaron modos diversos en que las subjetividades juveniles son signadas por las condiciones de acceso a la escolaridad en el Telebachillerato Comunitario de un contexto conurbado del sur del estado de México. El trabajo admite limitaciones en el dar cuenta de una realidad espacio-temporal concreta a través de la perspectiva estudiantil de un plantel, que si bien refiere a una articulación compleja de distintas dimensiones de realidad (social, política, cultural, educativa), difícilmente podría tratarse como un problema generalizable a otras realidades. Aunque se procuró un estudio contextualizado y dialógico se reconoce que las voces convocadas difícilmente se despojan del lugar de evidencia y que existe siempre el matiz subjetivo de quien las referencia e interpreta.

Si bien, la metodología basada en el taller de narrativa convocó al diálogo y a la escucha como modos pedagógicos para la participación juvenil en el TBC tiene límites para el seguimiento y sistematización acerca del grado de incidencia en la movilización del tradicional orden escolar y la política educativa a partir de las voces, códigos simbólicos y experiencias juveniles.

El alcance de la investigación es descriptivo-interpretativo y permite concluir que las narrativas de jóvenes estudiantes del TBC están suscritas por un acceso excluyente del ejercicio del derecho a la educación a través de una modalidad que, si bien se ha ocupado de hacer cumplir la obligatoriedad y la cobertura de la EMS, hay pendientes en el tema de la infraestructura, las dinámicas y la organización en el servicio que ofrece a las juventudes.

Las narrativas escolares constituyen formas concretas en que la juventud mexiquense significa su experiencia dentro de la institución escolar entre subjetividades desacreditadas 
que se configuran en una condición juvenil estructuralmente precarizada en lo material y simbólico. Paradójicamente, también la signan subjetividades con-movidas por la participación, que los posiciona y forma como sujetos de derecho en las luchas por el reconocimiento y demanda de condiciones no solo de acceso, sino también de democratización de las instituciones que habitan, exigiendo sobre todo un trato digno a su condición humana y espacios propicios para aprender.

Las narrativas escolares también dan cuenta de una precariedad objetiva que cala las biografías y marca límites en los itinerarios escolares y proyectos juveniles. Así, la subjetividad se configura entre narrativas escolares carenciadas en las que el TBC significa frontera, posibilidad de construir prospectivas para desarrollar actividades laborales o mejorar sus opciones, inclusive, continuar con estudios superiores, aunque no siempre se concreta.

Las voces juveniles evidenciaron que ejercer el derecho a la educación está vinculado con la formación de sujetos que producen y no solo consumen experiencia (Magendzo, 2001). Por tanto, escuchar e interpretar las narrativas escolares implica leer alusiones a la biografía enlazada con lo social y la resignificación de lo escolar y cultural en la condición juvenil en nuestro tiempo. Lo expuesto coincide con Espinosa y Pons (2017) en cuanto a que al narrar sus experiencias, los actores escolares (sean estudiantes, docentes, madres/padres de familia, comunidad/región) develan los significados culturales, posiciones, relaciones de poder, conflictos y sentidos que definen las acciones en un contexto regional dejando al descubierto los ejes que dan sentido a un currículo alternativo.

La interpretación de las narrativas escolares entrecruza las dimensiones: normativa, contextual, relacional y político-deliberativa que convocan a nuevas o renovadas colocaciones y propuestas epistémicas y metodológicas en el campo de juventud y escuela. La investigación tallerista propone trascender un trabajo extractivo para construir procesos políticopedagógicos de coproducción de conocimiento para potenciar interacciones participativas y equitativas desde el reconocimiento de los sujetos juveniles en las escuelas y en la investigación.

La participación juvenil, en espacios fundados en la circulación de la palabra y la escucha, potencia la interacción pedagógica en la inaplazable tarea de una política educativa y una escuela con jóvenes, de encuentro y coproducción de subjetividades y corresponsabilidad ética.

El alcance de la investigación revela un ejercicio comprensivo-interpretativo de cómo en las narrativas juveniles la escuela, en un tiempo de incertidumbre y distanciamiento social, aún 
simboliza horizonte y posibilidad. Sin embargo, resulta inaplazable reconocer la subjetividad y la participación como elementos que dan significado y sentido a la experiencia escolar, que se sostiene cotidianamente en relaciones que con-mueven en formas de micropolítica juvenil entre emociones, acciones y esperanza (Reguillo, 2014) que rebasan la dimensión cognitiva y del saber hacer.

Si bien, el Telebachillerato Comunitario es un servicio educativo que favorece la cobertura del nivel medio superior y la escolarización de jóvenes en contextos históricamente desfavorecidos, siguen pendientes estudios que crucen la mirada objetiva de los indicadores escolares con la dimensión subjetiva de la experiencia escolar juvenil en los contextos concretos. En ese sentido, se coincide con otras investigaciones que han revelado que el TBC incorpora a jóvenes antes excluidos del sistema escolar, pero no bajo las condiciones de equidad que se requieren (Estrada y Alejo, 2019; Escamilla, 2019).

El estudio coloca, en el debate de la política educativa, la investigación y las interacciones educativas, las narrativas escolares que denuncian un ejercicio desigual del derecho a la educación, producto de las brechas en las condiciones estructurales y de acceso a la escolaridad, así como de la incipiente participación en las decisiones y acciones de la vida escolar.

Desde una perspectiva crítica de la escuela es prioritario conocer cómo la subjetividad signa las narrativas escolares y está signada por las condiciones de acceso a la escolaridad. Resulta inaplazable considerarla en la construcción del espacio escolar dado que, la escuela y la política educativa definen juventud y que la juventud resignifica su discurso y orden excluyente al colocar demandas y propuestas desde sus experiencias y códigos simbólicos.

La investigación deja abierta la discusión en torno a que el derecho a la educación no se garantiza en lo normativo, prescriptivo y en el acceso a la escolaridad. Aunque las políticas educativas han sido de las más sólidas en materia de juventud, estas no han podido revertir la desigualdad en el acceso a la educación, ya que actualmente se registran en México más de 6 millones de jóvenes que no estudian ni trabajan (INEE, 2019).

Es un desafío político-pedagógico avanzar en renovadas comunidades educativas fundadas en el diálogo, la reflexividad colectiva y el reconocimiento de las juventudes como sujetos epistémicos, culturales, creadores de múltiples, insospechadas y viables formas de acción y participación que ponen al centro sus subjetividades y narrativas con la convicción de que, las jóvenes y los jóvenes desde la escuela, sin importar la duración de sus estancias, son capaces de construir, como apuntaba Zemelman (1997) lo históricamente posible, la utopía. 


\section{Referencias}

Bárcena, Fernando. (2005). La experiencia reflexiva en educación. Barcelona, España: Paidós.

Bárcena, Fernando., y Mèlich, Carles. (2014). La educación como acontecimiento ético Natalidad, narración y hospitalidad. Buenos Aires, Argentina: Miño y Dávila.

Berlanga, Benjamín. (2018). Narración y emergencia de subjetividades emancipadoras. México: CESDER-UCIRED.

Bolívar, Antonio. (2010). La investigación biográfico narrativa en educación. Entrevista a Antonio Bolívar. Revista de Educación, 1(1), 201-212. Recuperado de https://fh.mdp.edu.ar/revistas/index.php/r educ/article/viewFile/14/58

Bolívar, Antonio., Domingo, Jesús., y Fernández, Manuel. (2001). La investigación biográficanarrativa en educación. Madrid, España: La Muralla.

Borda, Fals. (2009). Una sociología sentipensante para América Latina. Bogotá, Colombia: CLACSO.

Cano, Agustín. (2012). La metodología de taller en los procesos de educación popular. Revista Latinoamericana de Metodología de las Ciencias Sociales, 2(2), 22-51 Recuperado de http://www.memoria.fahce.unlp.edu.ar/art revistas/pr.5653/pr.5653.pdf

Consejo Nacional de Evaluación de la Política del Desarrollo Social (CONEVAL). (2012). Informe de pobreza y evaluación en el estado de México. Distrito Federal, México: CONEVAL. Recuperado

de https://www.coneval.org.mx/coordinacion/entidades/SiteAssets/Paginas/Mexico/monye val/Informe\%20de\%20pobreza\%20y\%20evaluaci\%C3\%B3n\%202012 Estado\%20de\% 20M\%C3\%A9xico.pdf

Corona, Sara., y Kaltmeier, Olaf. (2012). En diálogo. Metodologías horizontales en Ciencias Sociales y Culturales. México: Gedisa.

Dirección General de Bachillerato [DGB]. (2019). Telebachilerato Comunitario en los Estados. Recuperado de https://www.dgb.sep.gob.mx/servicioseducativos/telebachillerato/ofi estados.php?id=mexico

Duschatzky, Silvia. (2008). La escuela como frontera. Argentina: Paidós.

Escamilla, Iraís. (2019). Telebachillerato comunitario: de un modelo de cobertura de la educación media superior a un modelo socio civil desde una política de juventud. En E. M. Sergio, El Telebachillerato Comunitario de la cobertura a la búsqueda de equidad (pp. 117-152). México: Universidad de Guanajuato-Colofón.

Estrada, Marcos., y Alejo, Jacinto. (2019). El Telebachillerato Comunitario de la cobertura a la búsqueda de equidad. México: Universidad de Guanajuato-Colofón. 
Espinosa, Iván., y Pons, Leticia. (2017). Valor pedagógico de las narrativas escolares. Configuración de currículos regionales. Revista Latinoamericana de Estudios Educativos (México), 47(1), 7-41. Recuperado de http://www.redalyc.org/articulo.oa?id=27050422002

Foucault, Michel. (1976). Vigilar y castigar. México: Siglo XXI.

Freire, Paulo. (1970). Pedagogía del oprimido. México: Siglo XXI.

Guzmán, Carlota., y Saucedo, Claudia. (2013). La investigación sobre estudiantes en México: Tendencias y hallazgos. En: Claudia, Saucedo, Carlota, Guzmán, Etelvina, Sandoval, y Jesús, Galaz (coords.), Estudiantes, maestros y académicos en la investigación educativa. Tendencias, aportes y debates 2002-2011 (pp. 27-35). México: ANUIES; COMIE.

Guzmán, Cintya., y Padilla, Laura. (2017). Exploración de dos Telebachilleratos Comunitarios desde la perspectiva de la eficacia y mejora escolar. REXE. Revista de Estudios y Experiencias en Educación, 16(32), 111-125. doi: https://doi.org/10.21703/rexe.2017321111257

Hernández, Gloria., López, Susana., y Salgado, Rocío. (2012). Contextos de exclusión educativa, adolescencia y juventud. Un estudio de tres municipios del estado de México. México: ISCEEM-PROMEP.

Hernández, Gloria., Salgado, Rocío., Benítez, José., y Velasco, María (2020). Intersubjetividades juveniles escolares. Comunidades de poder y comunicación. Informe de investigación. Toluca: ISCEEM-PRODEP.

Honnet, Axel. (1997). La lucha por el reconocimiento. Barcelona, España: Crítica.

Instituto Nacional para la Evaluación de la Educación (INEE). (2019). La Educación Obligatoria en México: Informe 2019. México: INEE. Recuperado de https://www.inee.edu.mx/wpcontent/uploads/2019/04/P11245.pdf

Jiménez, Julio. (2019). La constitución de los sujetos juveniles en los márgenes de la inclusiónexclusión escolar (Tesis Doctoral). Toluca, México: ISCEEM.

Knobel, Michel., y Lankshear, Colin. (2001). Maneras de ver: el análisis de datos en investigación cualitativa. México: IMCED.

Larrosa, Jorge. (2010). Herido de realidad y en busca de realidad. Notas sobre los lenguajes de la experiencia. En José Contreras y Nuria Pérez de Lara (comps.), Investigar la experiencia educativa (pp. 87-116). Madrid, España: Morata.

López, Susana., y Reyes, Carlos. (2019). La formación en el telebachillerato comunitario: las trayectorias sociales de jóvenes que lo abandonaron. Presentado en XV Congreso Nacional de Investigación Educativa. Acapulco, México. Recuperado de http://www.comie.org.mx/congreso/memoriaelectronica/v15/seccion4.htm 
Magendzo, Abraham. (2001). El derecho a la educación: una reflexión desde el paradigma Crítico y la educación en Derechos humanos. Ultima consulta realizada en octubre 21 de $2013 . \quad$ Recuperado de http://www.cifedhop.org/Fr/Publications/Thematique/thematique9/Magendzo.pdf

Medina, Gabriel. (2010). Tecnologías y subjetividades juveniles. En Rossana Reguillo (coord.), Los jóvenes en México (pp. 154-182). México: FCE.

Reguillo, Rossana. (2010). La condición juvenil en el México contemporáneo: Biografías, incertidumbres y lugares. En Rossana Reguillo (coord.), Los jóvenes en México (pp. 395429). México: FCE.

Reguillo, Rossana. (2014). Repensar la participación juvenil. Nuevas formas, nuevos retos. Recuperado de https://www.youtube.com/watch?v=zWb SxldyE.

Ricoeur, Paul. (2003). Sí mismo como otro. México: Siglo XXI.

Rodríguez Rocha, Eduardo. (2014). El rol de las elecciones educativas en la transición a la Educación Media Superior en la Ciudad de México. Revista Latinoamericana de Población, 8(15), 119-144. Recuperado de https://www.redalyc.org/pdf/3238/323835583006.pdf

Salgado, Rocío. (2018). Narrativas de mi experiencia escolar: emociones, relaciones y aprendizajes [Archivo personal de la autora].

Salgado, Rocío. (2019). La convivencia un constructo socioemocional. Aproximaciones desde la experiencia escolar juvenil y la investigación tallerista. Presentado en XV Congreso Nacional de Investigación Educativa . Acapulco, México. Recuperado de http://www.comie.org.mx/congreso/memoriaelectronica/v15/doc/1754.pdf

Salgado, Rocío. (2020). Derecho a la educación y subjetividades juveniles. Haciendo comunidades educativas en diálogo. Informe de Investigación. En G. Hernández, R. Salgado, J. Benítez y M. Velasco. Intersubjetividades juveniles escolares. Comunidades de poder y comunicación (pp. 53-94). Toluca: ISCEEM.

Saucedo, Claudia., Guzmán, Carlota., Sandoval, Etelvina., y Galaz, Jesús. (2013). Estudiantes, maestros y académicos en la investigación educativa. México: ANUIESCOMIE.

Sánchez, Oralia. (2019). Claroscuros de la inclusión/exclusión desde la experiencia educativa de los jóvenes con capacidades alternas (Tesis Doctoral). Instituto Superior de Ciencias de la Educación del Estado de México, Toluca, México.

Secretaría de Educación Pública [SEP]. (2018). Principales cifras del Sistema Educativo Nacional. México: SEP.

Secretaría de Educación Pública [SEP] y Dirección General de Bachillerato [DGB]. (2018). Documento Base 2018 Adopción del Modelo Educativo para la Educación Obligatoria en el Telebachillerato Comunitario. México: SEPDGB. 
Tójar, Juan. (2011). Disciplinas, paradigmas y tradiciones. Madrid, España: La Muralla.

Valenzuela, José. (2015). Juvenicidio: Ayotzinapan y las vidas precarias en América Latina y España. En J. M. Valenzuela, El sistema es antinosotros. Culturas, movimientos y resistencias juveniles. México: El Colef; ITESO; Ned Ediciones.

Weber, Max. (1971). Sobre la teoría de las ciencias sociales. Barcelona, España: Península.

Weiss, Eduardo. (2017a). Estudio exploratorio del Modelo de Telebachillerato Comunitario y su operación en los estados. México: INEE.

Weiss, Eduardo. (2017b). El Telebachillerato Comunitario. Una innovación curricular a discusión. Revista Latinoamericana de Estudios Educativos (México), 47(3-4), 7-25. Recuperado de https://www.redalyc.org/pdf/270/27054113002.pdf

Zemelman, Hugo. (1997). El futuro como ciencia y utopía. México: UNAM. 
Revista indizada en

scip/o

redalyc latindex

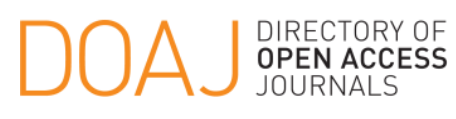

Distribuida en las bases de datos:

๑ Dialnet

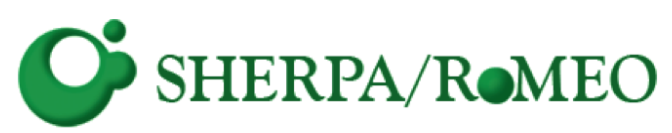

REDIB

Red Iberoamericana

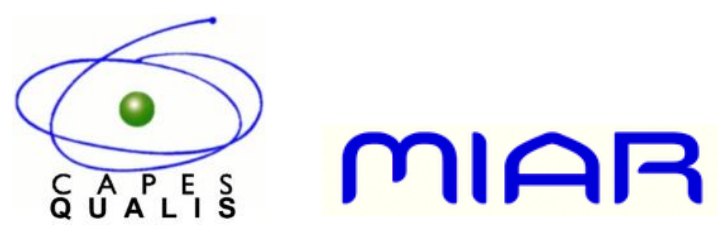

